\title{
An Update on the Intracellular and Intercellular Trafficking of Carmoviruses
}

\author{
José A. Navarro * and Vicente Pallás * \\ Instituto de Biología Molecular y Celular de Plantas, Consejo Superior de Investigaciones Científicas, Universitat Politècnica \\ de València, Valencia, Spain
}

\section{OPEN ACCESS}

Edited by:

Richard S. Nelson,

Noble Research Institute, LLC,

United States

Reviewed by:

Sergey Morozov,

Moscow State University, Russia

Miguel A. Aranda,

Consejo Superior de Investigaciones

Científicas (CSIC), Spain

*Correspondence:

Vicente Pallás

vpallas@ibmcp.upv.es

José A. Navarro

janavarr@ibmcp.upv.es

Specialty section:

This article was submitted to

Virology,

a section of the journal

Frontiers in Plant Science

Received: 10 August 2017 Accepted: 04 October 2017 Published: 18 October 2017

Citation:

Navarro JA and Pallás V (2017) An Update on the Intracellular and Intercellular Trafficking of Carmoviruses.

Front. Plant Sci. 8:1801. doi: 10.3389/fpls.2017.01801
Despite harboring the smallest genomes among plant RNA viruses, carmoviruses have emerged as an ideal model system for studying essential steps of the viral cycle including intracellular and intercellular trafficking. Two small movement proteins, formerly known as double gene block proteins (DGBp1 and DGBp2), have been involved in the movement throughout the plant of some members of carmovirus genera. DGBp1 RNA-binding capability was indispensable for cell-to-cell movement indicating that viral genomes must interact with DGBp1 to be transported. Further investigation on Melon necrotic spot virus (MNSV) DGBp1 subcellular localization and dynamics also supported this idea as this protein showed an actin-dependent movement along microfilaments and accumulated at the cellular periphery. Regarding DGBp2, subcellular localization studies showed that MNSV and Pelargonium flower break virus DGBp2s were inserted into the endoplasmic reticulum (ER) membrane but only MNSV DGBp2 trafficked to plasmodesmata (PD) via the Golgi apparatus through a COPII-dependent pathway. DGBp2 function is still unknown but its localization at PD was a requisite for an efficient cell-to-cell movement. It is also known that MNSV infection can induce a dramatic reorganization of mitochondria resulting in anomalous organelles containing viral RNAs. These putative viral factories were frequently found associated with the ER near the PD leading to the possibility that MNSV movement and replication could be spatially linked. Here, we update the current knowledge of the plant endomembrane system involvement in carmovirus intra- and intercellular movement and the tentative model proposed for MNSV transport within plant cells.

Keywords: carmovirus, intracellular movement, movement proteins, Golgi, endoplasmic reticulum, mitochondria

\section{INTRODUCTION}

Recent phylogenetic analysis of the amino acid sequences of the RNA dependent RNA polymerase (RdRp) of members of the genus Carmovirus support the redistribution of 15 out of 19 of these into three different genera, Alphacarmovirus [type member Carnation mottle virus (CarMV)], Betacarmovirus [type member Turnip crinkle virus (TCV)] and Gammacarmovirus [type member Melon necrotic spot virus (MNSV)]. The genus Carmovirus no longer exists as such, and therefore the remaining four former members have been currently unassigned pending appropriate classification (Adams et al., 2016). In general, carmoviruses have a narrow range of naturally occurring hosts. Alpha and betacarmoviruses cause diseases mainly in flowering ornamental plants 
and gammacarmoviruses occur in leguminous plants, with the exception of MNSV that is confined to species in the family Cucurbitaceae (Hull, 2002). All of them are mechanically transmissible by grafting and/or by contact between plants. In contrast, vector and/or seed transmission have only been reported for a few species (Martini, 1958; Teakle, 1980; Krczal et al., 1995; Herrera-Vásquez et al., 2009; Mello et al., 2010; Ohki et al., 2010).

All viruses in these new genera have spherical virus particles of about 30-35 $\mathrm{nm}$ in diameter and small simple genomes comprising a single molecule of linear plus-sense single-stranded RNA, around $4 \mathrm{~kb}$ in length. They also share a common genomic organization consisting of at least five open reading frames (ORFs) with most of them overlapping with each other (Guilley et al., 1985; Carrington et al., 1989; Riviere and Rochon, 1990) (Figure 1A). The 5'-proximal ORFs are expressed from the genomic RNA while the ORFs at the $3^{\prime}$ half of the genome are expressed from two subgenomic RNAs (Hull, 2002). The first ORF encodes a $25-29 \mathrm{kDa}$ auxiliary replicase protein and terminates in a leaky stop codon. A ribosomal readthrough mechanism generates an in-frame fusion product that varies from 81 to $89 \mathrm{kDa}$ and corresponds to the viral RdRp. The 3 -proximal gene encodes the coat protein $(\mathrm{CP})$ that also acts a suppressor of RNA silencing (Thomas et al., 2003; Genovés et al., 2006; Martínez-Turino and Hernández, 2009). The CP molecular weight varies between 37 and $39 \mathrm{kDa}$ with the exception of the MNSV CP that, with a size of $42 \mathrm{kDa}$, is morphologically much closer to tombusvirus than to carmovirus (Riviere and Rochon, 1990; Wada et al., 2008).

A distinctive feature in carmovirus genome organization is the presence of two centrally located ORFs encoding two small movement proteins (MPs) $(6-8$ and $6-13 \mathrm{kDa})$. Both have been demonstrated to be involved in cell-to-cell movement of species belonging to each new carmovirus grouping (Li et al., 1998; Genovés et al., 2006; Martínez-Turiño and Hernández, 2011). This is the reason why, by analogy with the well-known triple gene block proteins (TGBps) (Morozov and Solovyev, 2003), they have been often referred to as double gene block proteins (DGBp1 and DGBp2) (Hull, 2002).

\section{THE DOUBLE GENE BLOCK PROTEINS: STRUCTURAL AND FUNCTIONAL FEATURES}

The involvement of DGBps in cell-to-cell movement has only been demonstrated for TCV (Betacarmovirus), MNSV (Gammacarmovirus) and Pelargonium flower break virus, PFBV (Alphacarmovirus) by showing that specific mutations in either of the two DGB protein genes affected viral cell-to-cell movement (Li et al., 1998; Genovés et al., 2006; Martínez-Turiño and Hernández, 2011). The nature and the components of the carmoviruses entity that moves are not yet fully characterized but some observations suggest the CP involvement. Entire CP deletion mutants of MNSV and TCV considerably reduced the extent of local infection in melon and limited the cell-to-cell movement to a few cells in Nicotiana benthamiana, respectively.
In both cases, the normal extent of local movement was recovered when other well-established viral suppressors were provided in trans (Genovés et al., 2006; Powers et al., 2008; Shi et al., 2009). Therefore, the apparent effect of these CPs on cell-tocell movement was most likely associated with their ability to suppress RNA silencing (Qu et al., 2003; Thomas et al., 2003; Genovés et al., 2006; Serra-Soriano et al., 2017). Besides, the TCV CP was dispensable for cell-to-cell movement in Arabidopsis thaliana but it was essential to facilitate the entry of virions into the vasculature and cause systemic infection (Cohen et al., 2000a). Although more investigation is needed, this phenomenon could be attributable to differences in the silencing pathways between both plants. In any case, it is obvious that the intra- and intercellular transport of these viruses can take place in a non-encapsidated form in such a way that the contribution of both DGBps must be extremely relevant (Hacker et al., 1992; Cohen et al., 2000a; Genovés et al., 2006).

\section{DGBp1: The Putative Tractor of the Viral Genome}

Secondary structure predictions and alignment of DGBp1 amino acid sequences revealed that the highest degree of similarity among them was restricted to secondary structure elements, an indicative of functional significance (Navarro et al., 2006). Studies performed with CarMV and MNSV DGBp1s, revealed the presence of an $\alpha$-helical central region enriched in basic residues that modulate DGBp1 in vitro RNA binding (Figure 1B). The DGBp1-RNA recognition appears to occur via an "adaptive binding" mechanism by which both molecules change their conformation upon binding (Marcos et al., 1999; Vilar et al., 2001, 2005; Navarro et al., 2006). The DGBp1 C-terminus contains a potential $\beta$-sheet folding that can be involved in DGBp1 selfinteraction (Genovés et al., 2009) and protein-protein interaction.

The ability of the strain B of TCV to cause larger lesions and systemic symptoms in A. thaliana in a higher percentage than that caused by the strain $M$ was related to a difference in the affinity for RNA between their corresponding DGBp1s, and it was specifically due to a change from lysine in TCV-M DGBp1 to glutamate in TCV-B DGBp1 (Wobbe et al., 1998). MNSV cell-to-cell movement was extremely intolerant to any amino acid change that either reduced the global charge or provoked the destabilization of the secondary structure of the DGBp1 central region. Nevertheless, the $\mathrm{Nt}$ and $\mathrm{Ct}$ regions of the MNSV DGBp1 allowed a reduction in the number of basic residues before the movement was completely abolished. In these latter cases, the extent of the local infected area of each MNSV mutant directly correlated with the RNA affinity of the corresponding DGBp1 mutant protein. In view of these findings, DGBpl stands as a strong candidate for being the factor that binds the viral genome in order to initiate the transport toward the plasmodesmata (PD). It is well-known that plant viruses need to exploit $\mathrm{PD}$ to move from cell to cell and, in this sense, ectopically expressed MNSV DGBp1 was localized in motile granules that associated to actin microfilaments (MFs), showed actin-dependent movement at the cytoplasm and finally accumulated at the cellular periphery near the PD 


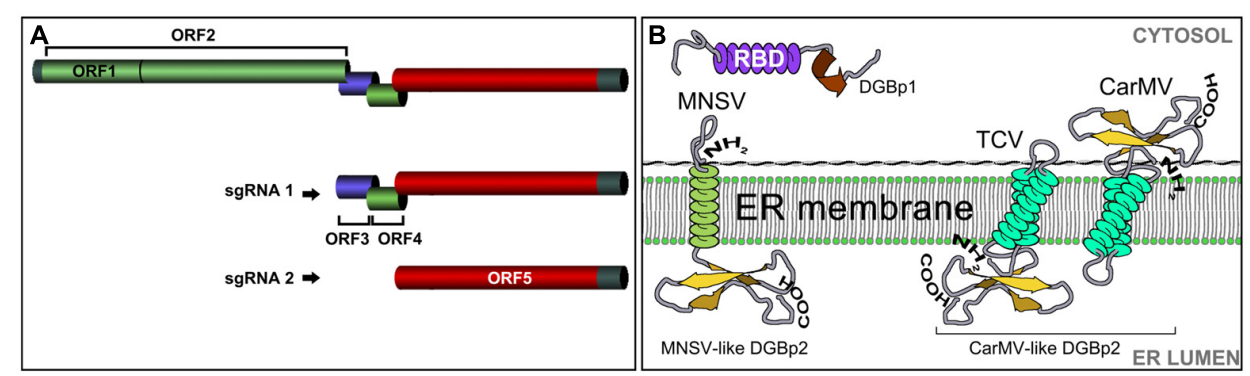

FIGURE 1 | (A) The organization of the carmovirus genome. ORF1: auxiliary replicase; ORF2: RNA dependent RNA polymerase; ORF3: double gene protein 1 (DGBp1); ORF4: double gene protein 2 (DGBp2); ORF 5: coat protein. (B) The organization of the DGB genes. The first DGB ORF encodes DGBp1 having a central RNA binding domain (RBD) rich in basic residues. DGBp2 is encoded in the second DGB ORF and has one (MNSV-like) or two (CarMV-like) transmembrane domains. Topology and membrane orientation of Melon necrotic spot virus (MNSV), Turnip crinkle virus (TCV), and Carnation mottle virus (CarMV) DGBp2s is shown.

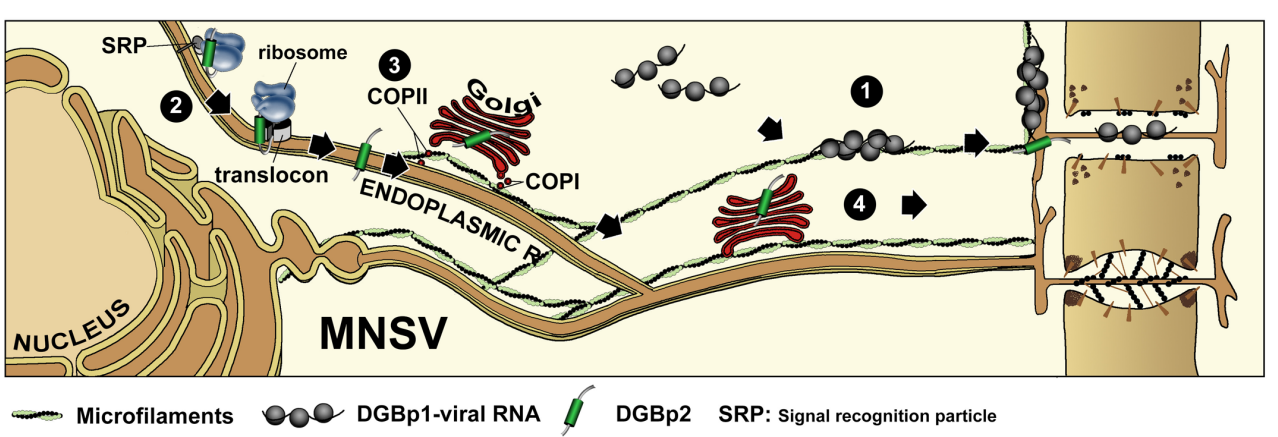

FIGURE 2 | Intracellular transport of double gene block proteins of Melon necrotic spot virus. MNSV DGBp1 and DGBp2 likely use two independent pathways to reach the cellular periphery and PD. Self-interacting DGBp1 molecules may bind vRNA to form RNPs that associate with actin microfilaments and move to cellular periphery in an actin-dependent manner (1). After cotranslational/signal recognition particle (SRP)-dependent and translocon-assisted insertion into ER membranes (2), MNSV DGBp2 is exported to the Golgi apparatus in a COPII-dependent pathway (3). Next, DGBp2 is targeted to PD via an unidentified post-Golgi route, or alternatively it can reach the PD by lateral diffusion along the ER (4).

(Figure 2). These DGBp1 mobile granules were not related with the major membrane bounded organelles and therefore could represent inclusion bodies consisting of self-interacting molecules (Genovés et al., 2009). Furthermore, subcellular fractionation experiments showed that, later in infection, CarMV DGBp1 mainly associated to the cell wall fraction (GarciaCastillo et al., 2003). In contrast, TCV DGBp1 showed a nuclear localization mediated by two nuclear localization signals (NLSs) that were necessary for cell-to-cell movement (Cohen et al., 2000b).

\section{DGBp2: The Membrane Associated Component}

The second MP found in carmoviruses (DGBp2) has been classified into two subgroups, namely MNSV-like and CarMV-like, depending on whether it has one or two potential transmembrane domains (TMDs) (Navarro et al., 2006; SerraSoriano et al., 2014). CarMV-like DGBp2s such as those of CarMV and TCV have been reported to be targeted and inserted in vitro into canine pancreatic rough ER-derived microsomes by means of a cotranslational/signal recognition particle (SRP)-dependent and translocon-assisted process (Sauri et al.,
2005; Navarro et al., 2006; Martínez-Gil et al., 2007, 2010). Their membrane topology was determined in vitro and the $\mathrm{N}$ - and C-terminal regions of the CarMV DGBp2 faced the cytoplasm whereas TCV DGBp2 showed an opposite orientation with both termini exposed to the ER lumen (Figure 1B) (Vilar et al., 2002; Martínez-Gil et al., 2007).

The MNSV and PFBV DGBp2s have also been demonstrated to associate to plant ER membranes but only the former was shown to be further targeted to $\mathrm{PD}$ via the Golgi apparatus (GA) in a COPII-dependent pathway (Figure 2) (Genovés et al., 2011). The PFBV DGBp2 differs from other CarMV-like DGBp2s in having an N-terminal extension with RNA-binding capacity and a leucine zipper-like motif that is probably involved in protein-protein interactions. PFBV DGBp2 ER export to other cellular membranes cannot be excluded since it was occasionally observed in unknown punctuate structures at the cytoplasm and close to the plasma membrane (Martínez-Turiño and Hernández, 2011). Genovés et al. (2011) also showed that the MNSV DGBp2 has a type II topology (Ncyt-Clum, Figure 1B) in plant cells as was previously described using bacteria (MartínezGil et al., 2007), but topological rules applicable in each case were different. MNSV DGBp2 mutational analysis revealed that neither a twofold increase in TMD hydrophobicity (von Heijne, 
2007) nor mutations that violate the positive-inside rule (LerchBader et al., 2008) resulted in opposite membrane orientation. Moreover, distortion of the TMD secondary structure was the unique determinant affecting the MP-membrane association suggesting a robust interaction with the ER. Despite this, most mutant proteins displayed an incorrect intracellular targeting to unidentified cytoplasmic vesicles or instead they produced a drastic rearrangement of ER membranes that impeded the protein to access the PD. After introducing these mutations into MNSV infectious RNAs, it was observed that the DGBp2 ER-to-GA transport was essential but not sufficient to promote cell-to-cell movement that strongly required the $\mathrm{PD}$ localization of the MP (Genovés et al., 2011). Although the plant GA has been reported to be the default destination for singlepass membrane proteins containing TMDs of about 19-20 amino acid in length (Brandizzi et al., 2002), the TMD of the MNSV DGBp2 by itself was unable to promote the ER-to-GA transport of the green fluorescent protein (GFP), resulting in ER retention. Actually, MNSV DGBp2 ER export was dependent on the specific contributions from a cytosolically exposed $\beta$-turn comprising DSSP residues and a luminal-oriented lysine (K49). Cytosolic exposure of the DSSP motif was essential to trigger Sar1 recruitment to ER membranes and protein ER export. Sar1 is a small GTPase that promotes the coat protein complex II (COPII) assembling and the formation of ER-to-GA transport vesicles. Mutations in the DSSP motif barely allowed MNSV to move into a few adjacent cells. These DGBp2 mutant proteins accumulated at the cellular periphery when it was transiently expressed suggesting that they still can reach the PD by lateral diffusion along the ER membranes. Therefore, DGBp2 needs to be targeted to the PD through the secretory pathway in order to achieve an efficient and fast viral transport to adjacent cells. Moreover, K49 was shown to be necessary for actin-dependent lateral diffusion of DGBp2 into the ER membranes, a condition that was essential for ER export. It was suggested that the connection of DGBp2 to the actin-ER network must require the interaction with an actin-associated transmembrane adaptor (Serra-Soriano et al., 2014). In this sense, it was shown that removing the anchoring aromatic amino acids that flank the MNSV DGBp2 TMD allowed the mutant virus to move farther than the wild type (Genovés et al., 2011).

Although the specific role of DGBp2 in viral transport is as yet unknown, an early model was proposed in which the DGBp2 cytosolic faced regions would interact with DGBp1 bound in turn to the viral RNA. This ternary complex would be translocated from the sites of replication to PD through the endomembrane system in a DGBp2-driven process (Vilar et al., 2002; Navarro et al., 2006). This was a striking and simple model, but it should be emphasized that MNSV DGBp1 and DGBp2 move intracellularly toward PD in the absence of other viral products through different and independent routes (Figure 2). These findings do not exclude the possibility that interaction between both DGBps takes place in the cellular periphery and, especially in the PD. This model is, however, hardly extensible to all carmoviruses. For instance, none of the TCV DGBps appears to be associated with punctate structures at the cell periphery or with the cytoskeleton. In addition, TCV
DGBp2 was found in both the nucleus and cytoplasm (Cohen et al., 2000a). Thus, it appears that the mechanism governing carmovirus movement could be more intricate than previously though.

\section{REPLICATION AND MOVEMENT CONNECTION IN CARMOVIRUS}

It is well-documented that viral RNA molecules must associate with MPs in order to be transported within and between cells. However, where and when this encounter should take place in the cell is still an open issue. Most positive-strand RNA viruses replicate their genomes in association with membrane structures derived from the ER and GA or from membrane-bound organelles (Verchot, 2011; Grangeon et al., 2012; Romero-Brey and Bartenschlager, 2014). This association leads to cytological modifications that cause a great impact within the cell by producing membranous compartments that, even morphologically different, can support viral complex assembling and replication (Jiang and Laliberté, 2016). The most remarkable cytological modification induced by carmoviruses is frequently related to mitochondria alterations. For example; PFBV induced enlargements of the mitochondrial cristae which often contained fibrillar material (Lesemann and Adam, 1994); an extensive peripheral vesiculation of mitochondria was observed in TCV-infected turnip cells (Russo and Martelli, 1982; Blake et al., 2007); and mitochondrial ultrastructural changes present in MNSV-infected melon cells were also dilated cristae, an evident matrix double membrane separation and rather large dilations inside them. Besides, dsRNAs were detected in these altered organelles (Gómez-Aix et al., 2014).

These findings make the mitochondria a plausible candidate to be the site for carmovirus replication. In fact, several reports with members of the three carmovirus genera have shown that the auxiliary replicase protein is targeted to mitochondria: immunoblot analysis of mitochondrial proteins from storage roots indicated that TCV p28 was associated with the mitochondria outer membrane (Blake et al., 2007); GFP fusions of p27 and RdRp (p86) of PFBV were located in mitochondria from plant and yeast cells (Martínez-Turino and Hernández, 2012); and fractionation of tissues expressing MNSV p29 and confocal imaging using GFP-p29 also shown that p29 associated with the mitochondrial membrane (Mochizuki et al., 2009). Based on data from related tombusviruses, it was proposed that the auxiliary replicase facilitates the formation of multimolecular complexes by interacting with the RdRp, the viral genome, and unidentified host factors. It is also assumed that the auxiliary replicase determines the subcellular localization of the replication complex (Panavas et al., 2005). One important point to consider in looking at this scenario is whether virus replication and movement are spatially separated or linked processes. A tightly association between replication and movement has been reported for a few viruses such as Tobacco mosaic virus (Kawakami et al., 2004; Liu and Nelson, 2013), Red clover necrotic mosaic virus (Kaido et al., 2009), Potato virus X (Tilsner et al., 2013), and Turnip mosaic virus (Grangeon et al., 2013). In the case 
of carmoviruses, however, it remains unclear how replication and movement are orchestrated.

Gómez-Aix et al. (2014) elegantly addressed the cytopathology of MNSV in melon cotyledons by transmission and focused ion beam-field emission scanning electron microscopy. They found that most of the mitochondria in infected cells contained large dilations enclosing numerous vesicles of $45-50 \mathrm{~nm}$ in length that were also observed along their external membrane. Interestingly, these vesicles were focusing toward the cytoplasm in close relationship with the ER. Altered mitochondria also contained viral particles and most likely unassembled $\mathrm{CP}$ as well as viral single and double stranded RNA molecules. In the same work, it was demonstrated that p29 could induce mitochondria reorganization and formation of structures with numerous dilations surrounded by double membranes. These findings strongly indicated that MNSV replication takes place in these abnormal organelles.

It has been shown that a protein complex, named endoplasmic reticulum (ER)-mitochondria encounter structure (ERMES), is located at the interface of the ER and the mitochondria providing a hub for fine communication between both organelles (Mueller and Reski, 2015). Although ERMES was not involved in PFBV p27 targeting to mitochondria in yeast (Martínez-Turino and Hernández, 2012), it is tempting to speculate that MNSV could take advantage of this complex to interconnect replication and movement. Interestingly, Gómez-Aix et al. (2014) reported a frequent association of the MNSV viral factories to the ER in close proximity to the $\mathrm{PD}$. This observation may suggest the presence of intercellular transport mechanisms functioning more directly in a similar way to that described for Potato virus $\mathrm{X}$ where viral RNA is coreplicationally delivered into the PD (Tilsner et al., 2013).

\section{CONCLUSION AND PERSPECTIVES}

Despite having the smallest genomes in the viral RNA world carmoviruses have turned to be ideal model systems for the study of essential processes for the viral cycle such as translation (Gao et al., 2012; Simon and Miller, 2013; Miras et al., 2014; Blanco-Perez et al., 2016), movement (Serra-Soriano

\section{REFERENCES}

Adams, M. J., Lefkowitz, E. J., King, A. M. Q., Harrach, B., Harrison, R. L., Knowles, N. J., et al. (2016). Ratification vote on taxonomic proposals to the International Committee on Taxonomy of Viruses. Arch. Virol. 161, 2921-2949. doi: 10.1007/s00705-016-2977-6

Blake, J. A., Lee, K. W., Morris, T. J., and Elthon, T. E. (2007). Effects of Turnip crinkle virus infection on the structure and function of mitochondria and expression of stress proteins in turnips. Physiol. Plant. 129, 698-706. doi: 10.1111/j.1399-3054.2006.00852.x

Blanco-Perez, M., Perez-Canamas, M., Ruiz, L., and Hernandez, C. (2016). Efficient translation of Pelargonium line pattern virus RNAs relies on a TED-like 3 '-translational enhancer that communicates with the corresponding 5 '-region through a long-distance RNA-RNA interaction. PLOS ONE 11:e0152593. doi: 10.1371/journal.pone.0152593

Brandizzi, F., Frangne, N., Marc-Martin, S., Hawes, C., Neuhaus, J. M., and Paris, N. (2002). The destination for single-pass membrane proteins is influenced et al., 2014), RNA silencing (Zhou et al., 2008; Zhang et al., 2012), membrane insertion (Vilar et al., 2002), and resistance mechanisms (Chandra-Shekara et al., 2004; Nieto et al., 2006). Although a significant progress has been made in knowing the viral determinants underlying these essential processes, the cellular aspects that could shed light on the real scenario in which these processes take place are lacking. It is evident that there is a need to study the subcellular localization of DGBps and their interactions during viral infection and to know more about how the virus-induced subcellular structures condition the plant cell function and allow viral infection. In addition, the physical entities that cross plasmodesmata or translocate through the phloem to allow the systemic invasion of the plant are far from being elucidated. Finally, during the last years an increasing number of cellular pathways have been reported to be remodeled by plant RNA viruses. Carmoviruses can be an ideal model to study how these pathogens subvert these pathways in their own benefit and can help to understand the mechanistic insights that operate at the cellular level.

\section{AUTHOR CONTRIBUTIONS}

All authors listed have made a substantial, direct and intellectual contribution to the work, and approved it for publication.

\section{FUNDING}

This work was funded by grant BIO2014-54862-R from the Spanish Direccion General de Investigacion Cientifica y Tecnica (DGICYT) and the Prometeo Program GV2014/010 from the Generalitat Valenciana.

\section{ACKNOWLEDGMENTS}

Authors want to acknowledge the excellent technical assistance of Lorena Corachan in the different research lines that made possible this review. The authors apologize to those whose work could not be cited due to space limitations.

markedly by the length of the hydrophobic domain. Plant Cell 14, 1077-1092. doi: $10.1105 /$ tpc. 000620

Carrington, J. C., Heaton, L. A., Zuidema, D., Hillman, B. I., and Morris, T. J. (1989). The genome structure of Turnip crinkle virus. Virology 170, 219-226. doi: 10.1016/0042-6822(89)90369-3

Chandra-Shekara, A. C., Navarre, D., Kachroo, A., Kang, H.-G., Klessig, D., and Kachroo, P. (2004). Signaling requirements and role of salicylic acid in HRT-and RRT-mediated resistance to Turnip crinkle virus in Arabidopsis. Plant J. 40, 647-659. doi: 10.1111/j.1365-313X.2004.02241.x

Cohen, Y., Gisel, A., and Zambryski, P. C. (2000a). Cell-to-cell and systemic movement of recombinant green fluorescent protein-tagged turnip crinkle viruses. Virology 273, 258-266. doi: 10.1006/viro.2000.0441

Cohen, Y., Qu, F., Gisel, A., Morris, T. J., and Zambryski, P. C. (2000b). Nuclear localization of Turnip crinkle virus movement protein p8. Virology 273, 276-285. doi: 10.1006/viro.2000.0440

Gao, F., Kasprzak, W., Stupina, V. A., Shapiro, B. A., and Simon, A. E. (2012). A ribosome-binding, $3^{\prime}$ translational enhancer has a t-shaped structure and 
engages in a long-distance RNA-RNA interaction. J. Virol. 86, 9828-9842. doi: 10.1128/JVI.00677-12

Garcia-Castillo, S., Sanchez-Pina, M. A., and Pallas, V. (2003). Spatio-temporal analysis of the RNAs, coat and movement (p7) proteins of Carnation mottle virus in Chenopodium quinoa plants. J. Gen. Virol. 84, 745-749. doi: 10.1099/ vir.0.18715-0

Genovés, A., Navarro, J. A., and Pallás, V. (2006). Functional analysis of the five Melon necrotic spot virus genome-encoded proteins. J. Gen. Virol. 87, 2371-2380. doi: 10.1099/vir.0.81793-0

Genovés, A., Navarro, J. A., and Pallás, V. (2009). A self-interacting carmovirus movement protein plays a role in binding of viral RNA during the cell-tocell movement and shows an actin cytoskeleton dependent location in cell periphery. Virology 395, 133-142. doi: 10.1016/j.virol.2009.08.042

Genovés, A., Pallás, V., and Navarro, J. A. (2011). Contribution of topology determinants of a viral movement protein to its membrane association, intracellular traffic, and viral cell-to-cell movement. J. Virol. 85, 7797-7809. doi: 10.1128/jvi.02465-10

Gómez-Aix, C., García-García, M., Aranda, M. A., and Sánchez-Pina, M. A. (2014). Melon necrotic spot virus replication occurs in association with altered mitochondria. Mol. Plant Microbe Interact. 28, 387-397. doi: 10.1094/MPMI09-14-0274-R

Grangeon, R., Jiang, J., and Laliberte, J. F. (2012). Host endomembrane recruitment for plant RNA virus replication. Curr. Opin. Virol. 2, 683-690. doi: 10.1016/j. coviro.2012.10.003

Grangeon, R., Jiang, J., Wan, J., Agbeci, M., Zheng, H., and Laliberté, J.-F. (2013). $6 \mathrm{~K}_{2}$-induced vesicles can move cell to cell during Turnip mosaic virus infection. Front. Microbiol. 4:351. doi: 10.3389/fmicb.2013.00351

Guilley, H., Carrington, J. C., Balazs, E., Jonard, G., Richards, K., and Morris, T. J. (1985). Nucleotide sequence and genome organization of Carnation mottle virus RNA. Nucleic Acids Res. 13, 6663-6677. doi: 10.1093/nar/13.18.6663

Hacker, D. L., Petty, I. T., Wei, N., and Morris, T. J. (1992). Turnip crinkle virus genes required for RNA replication and virus movement. Virology 186, 1-8. doi: 10.1016/0042-6822(92)90055-T

Herrera-Vásquez, J. A., Córdoba-Sellés, M. C., Cebrián, M. C., AlfaroFernández, A., and Jordá, C. (2009). Seed transmission of Melon necrotic spot virus and efficacy of seed-disinfection treatments. Plant Pathol. 58, 436-442. doi: 10.1111/j.1365-3059.2008.01985.x

Hull, R. (2002). Matthews' Plant Virology. London: Academic Press.

Jiang, J., and Laliberté, J.-F. (2016). "Membrane association for plant virus replication and movement," in Current Research Topics in Plant Virology, eds A. Wang and X. Zhou (Cham: Springer International Publishing), 67-85.

Kaido, M., Tsuno, Y., Mise, K., and Okuno, T. (2009). Endoplasmic reticulum targeting of the Red clover necrotic mosaic virus movement protein is associated with the replication of viral RNA1 but not that of RNA2. Virology 395, 232-242. doi: 10.1016/j.virol.2009.09.022

Kawakami, S., Watanabe, Y., and Beachy, R. N. (2004). Tobacco mosaic virus infection spreads cell to cell as intact replication complexes. Proc. Natl. Acad. Sci. U.S.A. 101, 6291-6296. doi: 10.1073/pnas.0401221101

Krczal, G., Albouy, J., Damy, I., Kusiak, C., Deogratias, J. M., Moreau, J. P., et al. (1995). Transmission of Pelargonium flower break virus (PFBV) in irrigation systems and by thrips. Plant Dis. 79, 163-166. doi: 10.1094/PD-790163

Lerch-Bader, M., Lundin, C., Kim, H., Nilsson, I., and von Heijne, G. (2008). Contribution of positively charged flanking residues to the insertion of transmembrane helices into the endoplasmic reticulum. Proc. Natl. Acad. Sci. U.S.A 105, 4127-4132. doi: 10.1073/pnas.0711580105

Lesemann, D. E., and Adam, G. (1994). Electron Microscopical and Serological Studies on Four Isometrical Pelargonium Viruses. Leuven: International Society for Horticultural Science (ISHS), 41-54. doi: 10.17660/ActaHortic.1994.377.3

Li, W. Z., Qu, F., and Morris, T. J. (1998). Cell-to-cell movement of Turnip crinkle virus is controlled by two small open reading frames that function in trans. Virology 244, 405-416. doi: 10.1006/viro.1998.9125

Liu, C., and Nelson, R. (2013). The cell biology of Tobacco mosaic virus replication and movement. Front. Plant Sci. 4:12. doi: 10.3389/fpls.2013.00012

Marcos, J. F., Vilar, M., Perez-Paya, E., and Pallas, V. (1999). In vivo detection, RNA-binding properties and characterization of the RNA-binding domain of the $\mathrm{p} 7$ putative movement protein from carnation mottle carmovirus (CarMV). Virology 255, 354-365. doi: 10.1006/viro.1998.9596
Martínez-Gil, L., Johnson, A. E., and Mingarro, I. (2010). Membrane insertion and biogenesis of the Turnip crinkle virus p9 movement protein. J. Virol. 84, 5520-5527. doi: 10.1128/jvi.00125-10

Martínez-Gil, L., Saurí, A., Vilar, M., Pallás, V., and Mingarro, I. (2007). Membrane insertion and topology of the p7B movement protein of Melon necrotic spot virus (MNSV). Virology 367, 348-357. doi: 10.1016/j.virol.2007.06.006

Martínez-Turino, S., and Hernández, C. (2009). Inhibition of RNA silencing by the coat protein of Pelargonium flower break virus: distinctions from closely related suppressors. J. Gen. Virol. 90, 519-525. doi: 10.1099/vir.0.006098-0

Martínez-Turiño, S., and Hernández, C. (2011). A membrane-associated movement protein of Pelargonium flower break virus shows RNA-binding activity and contains a biologically relevant leucine zipper-like motif. Virology 413, 310-319. doi: 10.1016/j.virol.2011.03.001

Martínez-Turino, S., and Hernández, C. (2012). Analysis of the subcellular targeting of the smaller replicase protein of Pelargonium flower break virus. Virus Res. 163, 580-591. doi: 10.1016/j.virusres.2011.12.011

Martini, C. (1958). "The transmission of turnip viruses by biting insects and aphids," in Proceedings of the $3 r d$ Conference on Potato Virus Diseases, (Wageningen: Veenman \& Zonen), 106-113.

Mello, A. F., Clark, A. J., and Perry, K. L. (2010). Capsid protein of Cowpea chlorotic mottle virus is a determinant for vector transmission by a beetle. J. Gen. Virol. 91, 545-551. doi: 10.1099/vir.0.016402-0

Miras, M., Sempere, R. N., Kraft, J. J., Miller, W. A., Aranda, M. A., and Truniger, V. (2014). Interfamilial recombination between viruses led to acquisition of a novel translation-enhancing RNA element that allows resistance breaking. New Phytol. 202, 233-246. doi: 10.1111/nph.12650

Mochizuki, T., Hirai, K., Kanda, A., Ohnishi, J., Ohki, T., and Tsuda, S. (2009). Induction of necrosis via mitochondrial targeting of Melon necrotic spot virus replication protein p29 by its second transmembrane domain. Virology 390, 239-249. doi: 10.1016/j.virol.2009.05.012

Morozov, S. Y., and Solovyev, A. G. (2003). Triple gene block: modular design of a multifunctional machine for plant virus movement. J. Gen. Virol. 84, 1351-1366. doi: 10.1099/vir.0.18922-0

Mueller, S. J., and Reski, R. (2015). Mitochondrial dynamics and the ER: the plant perspective. Front. Cell Dev. Biol. 3:78. doi: 10.3389/fcell.2015.00078

Navarro, J. A., Genovés, A., Climent, J., Saurí, A., Martínez-Gil, L., Mingarro, I., et al. (2006). RNA-binding properties and membrane insertion of Melon necrotic spot virus (MNSV) double gene block movement proteins. Virology 356, 57-67. doi: 10.1016/j.virol.2006.07.040

Nieto, C., Morales, M., Orjeda, G., Clepet, C., Monfort, A., Sturbois, B., et al. (2006). An eIF4E allele confers resistance to an uncapped and non-polyadenylated RNA virus in melon. Plant J. 48, 452-462. doi: 10.1111/j.1365-313X.2006.02885.x

Ohki, T., Akita, F., Mochizuki, T., Kanda, A., Sasaya, T., and Tsuda, S. (2010). The protruding domain of the coat protein of Melon necrotic spot virus is involved in compatibility with and transmission by the fungal vector Olpidium bornovanus. Virology 402, 129-134. doi: 10.1016/j.virol.2010.03.020

Panavas, T., Hawkins, C. M., Panaviene, Z., and Nagy, P. D. (2005). The role of the p33:p33/p92 interaction domain in RNA replication and intracellular localization of p33 and p92 proteins of cucumber necrosis tombusvirus. Virology 338, 81-95. doi: 10.1016/j.virol.2005.04.025

Powers, J. G., Sit, T. L., Qu, F., Morris, T. J., Kim, K. H., and Lommel, S. A. (2008). A versatile assay for the identification of RNA silencing suppressors based on complementation of viral movement. Mol. Plant Microbe Interact. 21, 879-890. doi: 10.1094/MPMI-21-7-0879

Qu, F., Ren, T., and Morris, T. J. (2003). The coat protein of Turnip crinkle virus suppresses posttranscriptional gene silencing at an early initiation step. J. Virol. 77, 511-522. doi: 10.1128/JVI.77.1.511-522.2003

Riviere, C. J., and Rochon, D. M. (1990). Nucleotide sequence and genomic organization of Melon necrotic spot virus. J. Gen. Virol. 71, 1887-1896. doi: 10.1099/0022-1317-71-9-1887

Romero-Brey, I., and Bartenschlager, R. (2014). Membranous replication factories induced by plus-strand RNA viruses. Viruses 6, 2826-2857. doi: 10.3390/ v6072826

Russo, M., and Martelli, G. P. (1982). Ultrastructure of Turnip crinkle- and Saguaro cactus virus-infected tissues. Virology 118, 109-116. doi: 10.1016/0042-6822(82) 90324-5

Sauri, A., Saksena, S., Salgado, J., Johnson, A. E., and Mingarro, I. (2005). Doublespanning plant viral movement protein integration into the endoplasmic 
reticulum membrane is signal recognition particle-dependent, transloconmediated, and concerted. J. Biol. Chem. 280, 25907-25912. doi: 10.1074/jbc. M412476200

Serra-Soriano, M., Navarro, J. A., and Pallás, V. (2017). Dissecting the multifunctional role of the N-terminal domain of the Melon necrotic spot virus coat protein in RNA packaging, viral movement and interference with antiviral plant defence. Mol. Plant Pathol. 18, 837-849. doi: 10.1111/mpp.12448

Serra-Soriano, M., Pallás, V., and Navarro, J. A. (2014). A model for transport of a viral membrane protein through the early secretory pathway: minimal sequence and endoplasmic reticulum lateral mobility requirements. Plant J. 77, 863-879. doi: $10.1111 /$ tpj. 12435

Shi, Y., Ryabov, E. V., van Wezel, R., Li, C., Jin, M., Wang, W., et al. (2009). Suppression of local RNA silencing is not sufficient to promote cell-to-cell movement of Turnip crinkle virus in Nicotiana benthamiana. Plant Signal. Behav. 4, 15-22. doi: 10.4161/psb.4.1.7573

Simon, A. E., and Miller, W. A. (2013). 3' Cap-independent translation enhancers of plant viruses. Annu. Rev. Microbiol. 67, 21-42. doi: 10.1146/annurev-micro092412-155609

Teakle, D. S. (1980). "Fungi," in Vectors of Plant Pathogens, ed. K. Maramorosch (New York, NY: Academic Press), 417-438. doi: 10.1016/B978-0-12-326450-3. 50021-8

Thomas, C. L., Leh, V., Lederer, C., and Maule, A. J. (2003). Turnip crinkle virus coat protein mediates suppression of RNA silencing in Nicotiana benthamiana. Virology 306, 33-41. doi: 10.1016/S0042-6822(02)00018-1

Tilsner, J., Linnik, O., Louveaux, M., Roberts, I. M., Chapman, S. N., and Oparka, K. J. (2013). Replication and trafficking of a plant virus are coupled at the entrances of plasmodesmata. J. Cell. Biol. 201, 981-995. doi: 10.1083/jcb. 201304003

Verchot, J. (2011). Wrapping membranes around plant virus infection. Curr. Opin. Virol. 1, 388-395. doi: 10.1016/j.coviro.2011.09.009

Vilar, M., Esteve, V., Pallás, V., Marcos, J. F., and Pérez-Payá, E. (2001). Structural properties of Carnation mottle virus $\mathrm{p} 7$ movement protein and its RNA-binding domain. J. Biol. Chem. 276, 18122-18129. doi: 10.1074/jbc.M100706200

Vilar, M., Saurí, A., Marcos, J. F., Mingarro, I., and Pérez-Payá, E. (2005). Transient structural ordering of the RNA-binding domain of Carnation mottle virus $\mathrm{p} 7$ movement protein modulates nucleic acid binding. Chembiochem 6 , 1391-1396. doi: 10.1002/cbic.200400451

Vilar, M., Saurí, A., Monne, M., Marcos, J. F., von Heijne, G., Pérez-Payá, E., et al. (2002). Insertion and topology of a plant viral movement protein in the endoplasmic reticulum membrane. J. Biol. Chem. 277, 23447-23452. doi: $10.1074 /$ jbc.M202935200

von Heijne, G. (2007). Formation of transmembrane helices in vivo-is hydrophobicity all that matters? J. Gen. Physiol. 129, 353-356. doi: 10.1085/jgp. 200709740

Wada, Y., Tanaka, H., Yamashita, E., Kubo, C., Ichiki-Uehara, T., NakazonoNagaoka, E., et al. (2008). The structure of Melon necrotic spot virus determined at $2.8 \AA$ resolution. Acta Crystallogr. Sect. F Struct. Biol. Cryst. Commun. 64, 8-13. doi: $10.1107 /$ S1744309107066481

Wobbe, K. K., Akgoz, M., Dempsey, D. M. A., and Klessig, D. F. (1998). A single amino acid change in Turnip crinkle virus movement protein $\mathrm{p} 8$ affects RNA binding and virulence on Arabidopsis thaliana. J. Virol. 72, $6247-6250$.

Zhang, X., Zhang, X., Singh, J., Li, D., and Qu, F. (2012). Temperature-dependent survival of Turnip crinkle virus-infected Arabidopsis plants relies on an RNA silencing-based defense that requires DCL2, AGO2, and HEN1. J. Virol. 86, 6847-6854. doi: 10.1128/JVI.00497-12

Zhou, Y., Ryabov, E., Zhang, X., and Hong, Y. (2008). Influence of viral genes on the cell-to-cell spread of RNA silencing. J. Exp. Bot. 59, 2803-2813. doi: $10.1093 / \mathrm{jxb} / \mathrm{ern} 141$

Conflict of Interest Statement: The authors declare that the research was conducted in the absence of any commercial or financial relationships that could be construed as a potential conflict of interest.

Copyright (c) 2017 Navarro and Pallás. This is an open-access article distributed under the terms of the Creative Commons Attribution License (CC BY). The use, distribution or reproduction in other forums is permitted, provided the original author(s) or licensor are credited and that the original publication in this journal is cited, in accordance with accepted academic practice. No use, distribution or reproduction is permitted which does not comply with these terms. 